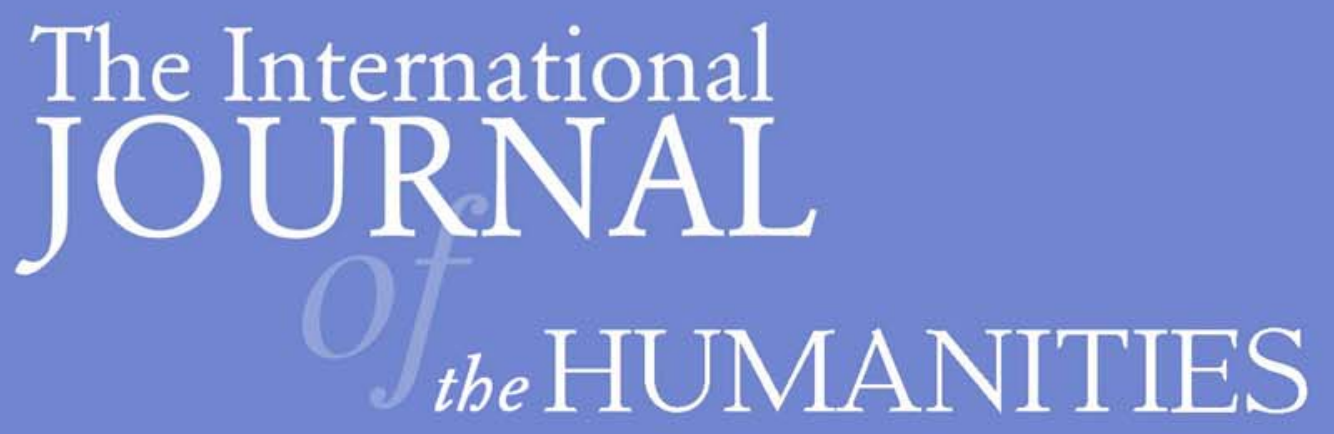

\title{
Handmade Films
}

Marina Estela Graca

VOLUME 3 


\section{INTERNATIONAL JOURNAL OF THE HUMANITIES}

http://www.Humanities-Journal.com

First published in 2005 in Melbourne, Australia by Common Ground Publishing Pty Ltd www.CommonGroundPublishing.com.

(C) 2005 (this paper), the author(s)

(c) 2005 (selection and editorial matter) Common Ground

All rights reserved. Apart from fair use for the purposes of study, research, criticism or review as permitted under the Copyright Act (Australia), no part of this work may be reproduced without written permission from the publisher. For permissions and other inquiries, please contact <cg-support@ commongroundpublishing.com>.

ISSN: $1447-9508$ (print), 1447-9559 (online)

Publisher Site: http://www.Humanities-Journal.com

The INTERNATIONAL JOURNAL OF THE HUMANITIES is a peer refereed journal. Full papers submitted for publication are refereed by Associate Editors through anonymous referee processes.

Typeset in Common Ground Markup Language using CGCreator multichannel typesetting system http://www.CommonGroundSoftware.com. 


\title{
Handmade Films
}

\author{
Questioning and Integrating Cinematic Technology \\ Marina Estela Graca, Aalborg University, Denmark
}

\begin{abstract}
Norman McLaren's most important creation strategy was that of making a film completely by hand: not only the visuals, which he painted or scratched directly on film, but also sound and-most important-motion. He propounded muscular memory to control the formal differences between successive images (1976/1978), proclaiming the physiological development of a consciousness of movement and thus neglecting what has always been considered up to now the main ontological foundations of film: the automatic recording of physical reality. At the same time he was questioning the epistemological model they integrate, i.e. the perception of order and the ways in which that order is imposed upon reality by films and the technology which holds them. In this paper I will try to demonstrate that, by overwhelming the cinematic technical workings with his gesture - literally with his body - Norman McLaren exposed its technological scheme to contingency, thus opening the production process to new unpredictable expressive and communicative possibilities. I will attempt to explain how this corresponds to a renewed way of comprehending technology by, simultaneously, revealing the human reality it contains and physiologically incorporating it.
\end{abstract}

Keywords: Film Theory, Direct-on-film Animation, Norman McLaren, Technology, Body

$\mathrm{T}$

HE GENERAL GOAL of my research is to find out what is questioned whenever an animated film is made by an author that chooses to have maximum control over the device automatisms. I am trying to understand in what ways that specific kind of film relates with Cinema and History of Art as a whole and, more specifically, how it is built within cinematic codes, workings and machinery.

In this paper, I aim to establish that each time an author makes a film by suspending both automatic 'motion' and image recording functions - that which is often known as 'cameraless' film - he initiates, simultaneously, a process that questions not only Cinema, within both expression and technology, but also the ontological position cinematic technology occupies in current media.

The illusion of motion constitutes the most important defining aspect of cinema. Usually the process of producing such an illusion begins by starting the automatic film recording process of moving visible objects at a ratio of 24,25 or 30 frames per second. Within animation techniques the recording process is reduced to a single frame each time the camera is turned onoff, much as if we were using a photographic camera. In both processes the visual configurations will be automatically photographed and put into a sequence of frames by the camera. However, there is one exceptional technique by which the filmmaker suspends all film recording automatisms and creates the sequence of images by marking directly the film stock. These films are known as 'cameraless' or 'handmade' animation films.

Over the past thirty years, anguish about the changes within cinema has taken hold of many minds, an anguish that is mainly technological in nature. Today, films are no longer made the way they once were. Digital technologies are being preferred in many filmmaking processes and, thus, the physical medium on which images are recorded - or saved is no longer physically accessed and manipulated the way it once was.

Nevertheless, I am convinced that a close look at uncommon studio filmmaking practices - such as those supported by cameraless techniques - might be imperative, as they have undoubtedly questioned and changed cinema technologies and production standards. Despite their fundamental importance, within a short time (since they remain almost unnoticed by film scholars), it might be difficult to understand their ontological position and influence in current cinema. These are practices that have challenged the dominant concepts of film production and cinema, as much as they don't conform with the 'cinematographic apparatus' (Baudry 1970 and 1975) that film theory still continues to propound, although our understanding of cinematic workings has come a long way since the 1970 s. Certainly, we cannot conceive a film production where all photographic recording procedures have been substituted by the hand drawing or engraving of images directly on the film stock - hence, where all image recording functions have been not only suspended but completely 
ignored - consistent with a model that establishes the photographic recording process to be essential to the equally essential 'impression of reality' created within the 'subject' unconscious, upon which the very basic concepts of cinema and film have been built.

By 1986, the French Canadian filmmaker Pierre Hébert - who started his career with Norman McLaren at the National Film Board of Canada invented an unusual kind of performance (live scratched animation $^{1}$ ) which took him to perform in many countries in Europe and North America. In those performances he improvised live cinematic dialogs with musicians such as Fred Frith, Robert Marcel Lepage, Jean Derome, René Lussier, and Bob Ostertag whom he met in 1989. Since then Hébert has collaborated with Ostertag on many Living Cinema projects, the most recent being Portrait of Buddha in which computers are used to process live handanimated images and sound in front of an audience $^{2}$.

Speaking at the Images Festival, Hébert pointed what he thinks is the most interesting aspect of scratching the illusion of motion directly on film:

"What I like in scratching on film is its deep anachronical character. It's a technique where there is a sort of historical short circuit. When you decide to disregard the photochemical technology of film you take a very naive stance, saying 'well, this is supposed to bear an image, so I will scratch an image on it, using a gesture that is as old as humanity.' I understood that there was in this a critical or remote stance, and it could be quite provocative, a statement about the historicity of technology". (Hébert in Gehman 2001)

All animated films rely on the same technological inventions upon which stands the entire cinema industry. Up to the present time - if we consider handmade films as an exceptional practice - this usually meant the photographic recording of visible objects. Today it also means the use of specific software applications based on algorithms that embed optical and rendering workings of photography.

Within this context, contemporary studio animation production became the result of a complicated process of capture or introduction of data, and calculations made by machines controlled by a large team of individuals, each of them specialized in different functions of specific tools, which have to communicate among each other through strict standard technical procedures and protocols. Their margin of express- ive freedom is limited so as to ascertain both the coherence of all film formal aspects and production management within available technology and budget. We may have a glimpse of this complex and very specialized production hierarchy by scrutinizing the end titles of any recent animation feature film produced by companies as DreamWorks Animation, Pixar Animation Studios or even Walt Disney Studios.

Handmade animation films were used in two different occasions as a normal and recurring studio production strategy. They were first made by Len Lye during the mid thirties, at the General Post Office Film Unit, headed by John Grierson. Lye developed the technique of painting directly on film that another Grierson protégé, Norman McLaren, would continue to investigate first at the G.P.O. and, later, at the N.F.B. of Canada.

McLaren first experimented with cameraless filmmaking (1934) - by drawing both the visuals and the sound score directly on celluloid - when he still was a student at the Glasgow School of Art. He discovered 'animated sound' then, by accidentally making marks with pen and ink on the soundtrack area of the film, a strip about $2 \mathrm{~mm}$ wide which runs along one of the edges on $35 \mathrm{~mm}$ film. A few years later, already working at the G.P.O., in London, under the influence of Len Lye and, also, the German Oskar Fischinger experiments, he achieved his first hand-drawn film, Love On The Wing (1938), for the new airmail service promotion purposes.

At the beginning of 1940, he was to accept a position at the N.F.B., invited by Grierson who, in the meantime, had been appointed as the first government film commissioner of Canada. McLaren would set up the board's animation unit in 1942, and - using the technique of animating directly on film - produced brief trailers like Mail Early (1941), V For Victory (1941), Five For Four (1942), Hen Hop (1942), and Dollar Dance (1943). Throughout his life he would make other films as important as Begone Dull Care (1949), Blinkity Blank (1955) or Synchromy (1971), among many, using the same technique.

Handmade animation made directly onto $35 \mathrm{~mm}$ or $16 \mathrm{~mm}$ film, as other forms of animation, aims to produce an illusion of motion. That can be achieved either by drawing, painting or stencilling sequential graphic forms onto clean transparent film or by engraving into opaque black one. It means to make 24 almost identical images by hand for each second on a surface as big as a thumbnail. The problem is to create meaningful forms in such a tiny space so they match from frame to frame into a convincing move-

\footnotetext{
${ }^{1}$ Two introductory articles about Pierre Hébert's film work, written by Chris Robinson and by Andrea Martignoni, are available at the Animation World Magazine web site.

${ }^{2}$ Information about Pierre Hébert's and Bob Ostertag's Living Cinema projects is available at Bob Ostertag's web site.
} 
ment. When working into black film stock the difficulties increase enormously as the opacity doesn't allow the use of grids or images as reference. The scratching is also very problematic due to the hardness of the emulsion.

Here is how Len Lye describes is work on his film Free Radicals (1958):

"When you hold the needle you dig it through the black emulsion into the film and then start doing kinds of pictographic signatures. You hold your hand at the right height and act as if you were to make your signature. It goes on forever. You can carry a pictographic design in your head and make a little design. You can't see what you're doing because your hand is in the way. That's why those things have that kind of spastic look..." (Len Lye in Russett \& Starr 1988, 68)

There is an obvious direct physical relationship between the artist and the film itself. With their intimate connection to the body, handcraft processes reintegrate not only the physical senses into filmmaking, for both the maker and viewer, but cinematic technology all together.

On a purely economic level, handmade films are not expensive. More pertinently, they free the studio from a reliance on complex technology and services. In his quest for alternative affordable and flexible film forms and practices, McLaren would be followed by some (then) young filmmakers at the board, such as Pierre Hébert and Caroline Leaf. With regard to the working attitude under McLaren's supervision, Hébert would state:

“[...] McLaren's idea of animation [was] one dominated by the personal and immediate activity of its creator and maximum freedom with the technical mechanisms. The upshot of this was that the Studio wasn't organised according to a hierarchy of functions or tasks to be met, but above all else as a community of creatives, invariably characterized by the widest range of technical choices, with a clear predominance of hand-made methods, and always open to the new."3

Norman McLaren left us with only a few writings. Most of all, they are explanations and guidelines about his animation techniques, made for the benefit of those who were curious about the 'secrets' underlying his work. Instead of stressing, with respect to the elaboration of films, the logical priority of industrial standards, McLaren kept suggesting that one should focus on the absolute priority of personally handling the technical mechanisms within the process of film construction itself. He wrote:

"To sum up, the conception and execution of most of my work for the National Film Board has probably depended on four things:

1) Attempting to keep at a minimum the technical mechanism standing between my conception and the finished work.

2) Handling personally the mechanisms that do remain, in as intimate a way as a painter his painting, or a violinist his violin.

3) Making the very limitations of these mechanisms, when brought in touch with the theme, the growing point for visual ideas.

4) Making sure of a chance for improvising at the moment of shooting or drawing." (1948)

It seems clear that he was struggling to bring technology within the reach of human experience, to the distance of his hand. The alternative would have been to become part of the production line as a functionary of the technical scheme within the apparatus: that is, behaving in accordance with its set of functions and functioning.

He was particularly rigorous in his attention to the sedimentation of the models proposed by the camera and the way in which they could be set adrift. In the essence of his practice there crops up the deepest desire to decipher (greater than the desire to experiment/experience and to show) which takes on a special relevance when seen in the context of the devices that sustain the cinematographic industry and communication.

Cinema does not exist without recourse to technology, and machinery, as we know, abides by the principles of reliability, presupposing a world built on cause and effect, a world that is predictable, turned in on itself, tautological and without boundaries. There is no author in the machine-controlled process: the essence of the creative process resides in the idealisation of the tool itself and not in what it can produce. There are only users in the context of the qualities and limitations imposed by the condition of the technical object. Hence, for those working with them within a creative process, the work only has meaning as a form of appropriation (both as auscultation and as expression) of the world based on a sensibility reshaped by the tool: to decipher the singularly attractive enigma of a pleasure that is inseparable from developments extending beyond the sphere of organic sensibility, forcing it to make constant emotional changes, of the kind that reach into and enrich the realms of the intellect, that

\footnotetext{
${ }^{3}$ Pierre Hébert, "Un mot de Pierre Hébert, producteur responsable du Studio d'animation du Programme français de l'Office national du film du Canada", accessible at www.onf.ca, 1996- Dec.1999, during his time heading the N.F.B. Animation French Studio.
} 
lead to undertaking actions on the material, on the senses, and also in an appeal to another's spirit, calling for the combined exertion of all human capacity, of all the human experience in the world.

Which is why McLaren has always stood up in his work for the obstinate translation of contingency in need. Recourse to the irregular (on the edge: verging on accident and mistake) rehumanizes the procedure, releasing the expressive work from the predictable ostensibility of technology, providing unexpected alternatives in the meaning-giving processes, boosting receptiveness to the transgression of protocol procedures, opening up to expressive results that go beyond programmed sanctions and that prescribed by functional reliability. It follows that maximum freedom and autonomy in building film discourse would only become possible through delimiting, questioning and suspending the exclusive character of the devices that support cinema. It is within this framework that McLaren's declarations on the main factors defining his work take on particular importance.

In the heart of his studio, McLaren directed filmmaking as a means of technical research, but also as a unique coming together of people and devices able to afford an aesthetic encounter, that is, a perceptible, shared experience with the meaning of "Community of creatives".

Clearly, one of McLaren's greatest aspirations would be to face up to what is truly communicated (communed) in the most essential part of each person's humanity. This is manifest in the formal principles structuring his work, but also in his working relations. It was almost as if his films were progressively becoming the means to a certain productive connection, as if the work had no meaning except as a form of physically and emotionally integrating the human experience, which could only be plural and differentiated: "It was a sharing kind of experience." remarked Grant Munro, another N.F.B. director, "You never worked for Norman, you always worked with him" (Grant Munro in Starr 1995).

Directing the film sets its own limits as a space of dialogue and differentiation, turned simultaneously onto the world and its own conditions of possibility. A place of suspension, opened up at the very brink of the conventional, and of revelation of what is not yet shared. The important thing would be to identify possibilities for give and take, fertile associations, and to differentiate the role of the elements. This explains the importance of others who are equally autonomous in the creation process, inasmuch as expression appears in the space where languages flow together and clash, as an exchange of energies, as a manifestation of an identity emerging from the differentiation and transfiguration of values and figures: the place of separation, from which the author, like each of his collaborators, reaches a maturation, a consciousness of himself and his own autonomy in accomplishing the work; the place of association and sharing, of communication, through the emergence of the new, a surprising apparition emerged from efforts negotiated between each person involved and who remain united by the very act of creation as a palpable experience and definitive engagement.

\section{Conclusion}

In other words, and to conclude, the name of Norman McLaren not only relates to a body of film work, in which each film appears as being what it formally is, but also as a context in which discourse, means of production and communication process (which, in the case of animation, depends exclusively on technology), are thrown into question and re-created as expression. The handmade film appears not only as a means of representation, as a support for something else, but in itself: as a presence. Within the communication model that emerges, in the abstract, from this method of making animation, the means ceases to be separate, an exclusive translator of an inaccessible world for a passive and paralysed receiver. The film would be in the world at the same level as the spectator, just as the world is in the film, within those who observe it and those who made it. Expression and presence take the place of representation.

More concretely, the attitude of appropriation guiding McLaren's production process presupposes a poetics that is simultaneously focused on the work of producing the film discourse and on the historical and cultural context from which it emerges. It establishes itself as a means for differentiating and harmonizing the different relations existing prior to the film (the listening to inner and exterior reality, observation of the singular and the emblematic, exploration of the specificity and technical limitations of technical and expressive media, the meaning emerging from the projection of previous experiences, whether successful or otherwise, the inference and inclusion of the spectator) but also as a means of appropriating the film context modified by the film itself, as a circumstance, an updating and (pre)text that allows for the creation of a space of possibilities within the heart of the established and the (not yet) perceived.

While making their films, authors like Len Lye, Norman McLaren or Pierre Hébert seem to have developed some sort of experimental epistemology (a study of how the brain represents knowledge and belief) through the physiological appropriation of one of the most dominant technologies of our time. Doing so, they have not only brought out new assumptions - as shapers of sensibility and thought but they have established new possibilities within 
the functioning of technology itself and also film creation. They have questioned, affronted and improved the concepts behind cinematic technological evolution towards new unexpected ontological possibilities.

\section{References}

Baudry, J.-L. (1970). "Effets idéologiques produits par l'appareil de base.” Cinéthique, n7/8, Paris.

Baudry, J.-L. (1975). "Le dispositif: approches métapsychologiques de l'impression de réalité." Communications, n²3, Paris.

Gehman, C. (2001). "Pierre Hébert: Animation without Borders - filmmaker." Take One, Montréal.

Hébert, P. (1985). "Éloge de la fixité-2." Format Cinéma, n44, Montréal.

Hébert, P. (1989). "Les enjeux de l'art à l'ère des machines, Effacement et résistance du corps.” 24 images, n43, Montréal, (22-27).

Hébert, P., (1999). L'Ange et l'automate. Québec: Les 400 coups.

Len, L. (1963 \& 1967). "Interview by Gretchen Berg." Film Culture, in Russett, R., and C. Starr (1988). Experimental Animation, Origins of a New Art. New York: Da Capo Press (68).

Lye, L. (1964). “The art that moves”, in Wystan Curnow \& Roger Horrocks (eds.) (1984). Figures of Motion, Selected Writings. Auckland: Auckland University Press, pp.78-87.

Martignoni, A. (1997). “The Burgeoning of a Project: Pierre Hébert's La Plante humaine.” Animation World Magazine, Issue 2.1, <http://www.awn.com/mag/issue2.1/articles/martignoni.e2.1.html > retrieved the 6th May 2006.

McLaren, N. (1948). “Animated Films.” Documentary Film News (52-53).

McLaren, N. (1958). Cameraless Animation. Information and Promotion Division, National Film Board of Canada

Ostertag, B. (2006). "Live Projects: Living Cinema." Bob Ostertag's web site <http://bobostertag.com/music-liveprojectslivingcinema.htm $>$, retrieved the $6^{\text {th }}$ May 2006

Robinson, C. J. (2001). "Pierre Hébert and Animation in the Age of Digital Reproduction". Animation World Magazine, $<$ http://mag.awn.com/index.php?ltype $=$ cat\&category $1=$ People\&article_no $=843 \#>$, retrieved the 6th May 2006.

Russett, R., and C. Starr (1988). Experimental Animation, Origins of a New Art. New York: Da Capo Press.

Starr, C. (1995). "Conversations with Grant Munro and Ishu Patel: The influence of Norman McLaren and the National Film Board of Canada.” Animatiom Journal, Spring (44-61).

\section{About the Author}

Marina Estela Graca

Animation Filmmaker, Researcher, Lecturer 

THE INTERNATIONAL JOURNAL OF THE HUMANITIES

EDITORS

Tom Nairn, RMIT University, Melbourne.

Mary Kalantzis, RMIT University, Australia.

EDITORIAL ADVISORY BOARD

Fethi Mansouri, Deakin University, Melbourne, Australia.

Paul James, RMIT University, Australia.

Juliet Mitchell, Cambridge University, UK.

Siva Vaidhyanathan, New York University, USA.

Patrick Baert, Cambridge University, UK.

Ted Honderich, University College, London.

Krishan Kumar, University of Virginia, USA.

David Christian, San Diego State University, California, USA.

Giorgos Tsiakalos, Aristotle University of Thessaloniki, Greece.

Gayatri Chakravorty Spivak, Columbia University, USA.

Mick Dodson, Australian National University, Canberra, Australia.

Jeffrey T. Schnapp, Stanford University, USA.

Nikos Papastergiadis, University of Melbourne, Australia.

Bill Kent, Monash Centre, Prato, Italy.

Chris Ziguras, RMIT University, Australia.

Eleni Karantzola, University of the Aegean, Greece.

Bill Cope, Common Ground, Australia.

ASSOCIATE EDITORS, 2005

Visit: http://www.Humanities-Journal.com

SCOPE AND CONCERNS

Visit: http://www.Humanities-Journal.com

SUBMISSION GUIDELINES

Visit: http://www.Humanities-Journal.com

INQUIRIES

Email: cg-support@ commongroundpublishing.com 